\title{
PEMBINGKAIAN BUDAYA JAWA DAN BELANDA DI DALAM NOVEL BUMI MANUSIA
}

\author{
${ }^{1}$ Denasya Nasution, ${ }^{2}$ Said Fadhlain, ${ }^{3}$ Reni Juliani \\ 1,2,3Program Studi Ilmu Komunikasi, Universitas Teuku Umar, Indonesia
}

Email: $\underline{\text { denasyanasution@gmail.com }}$

\begin{abstract}
The novel Bumi Manusia is a controversial novel that contains Indigenous life in the Dutch colonial period. Pram depicts the cultural differences between Indigenous and Dutch with a very contrast in all aspects in more detail and depth. The purpose of this research is to expose the cultural differences which are framed in the novel Bumi Manusia. This research is also intended to expose the differences between Javanese and Dutch cultures which not only distinguish culture based on appearance and language. This research is a qualitative descriptive study with secondary data which are obtained from the library research, in the form of literature which are related to this research. The results of this study are: 1) Culture can affect one's personality and mindset. 2) The author describes broader cultural differences and is able to criticize the social gap or strata which are formed from the different cultures at the same time.
\end{abstract}

Keywords :Framing Analysis, Media Studies, Bumi Manusia

\section{A. PENDAHULUAN}

Komunikasi memiliki beberapa bentuk komunikasi antar pribadi, kelompok, dan komunikasi massa. Komunikasi massa merupakan komunikasi menggunakan media massa untuk menyampaikan pesan-pesan seperti seorang pengarang menyampaikan pesan-pesan melalui bahasa atau simbol tertentu kepada pembaca.

Eriyanto (Chisanty, 2012:32) menjelaskan media bukan sekedar sasaran yang bebas karena media juga subyek yang melakukan konstruksi terhadap realtas, lengkap dengan pandangan bisa dan pemihakannya.Sama halnya dengan framing yang terjadi pada media berita dimana penulisnya menonjolkan di sisi - sisi tertentu.Begitu juga penulis novel Bumi Manusia menonjolkan sisi kebudayaan antara Jawa dan Belanda yang bertolak belakang pada masa itu.

Bumi Manusia merupakan novel pertama tetralogy.Buku yang ditulis oleh Pramoedya Ananta Toer (Pram) ini ditulis di Pulau Baru pada saat Pram menjadi tahanan pada tahun 1975.Novel yang berisikan kritikan sosial budaya yang sangat kontras antara nilai-nilai tradisi dan modern.Setiap karakter yang berada dalam buku ini tidak hanya berhasil menggambarkan revolusi budaya di Indonesia yang saat itu menjadi negara terjajah tapi juga berisikan penolakan pengagungan absolut budaya (Hastuti, 2018: 64).

Pribumi pada masa hindia Belanda banyak berinteraksi dengan bangsa Eropa Belanda dalam kesehariannya.Antara budaya pribumi dan Belanda memiliki perbedaan yang sangat signifikan dari dua etnis tersebut.Gaya hidup pribumi yang cenderung sederhana menjadi sangat mencolok perbedaannya dengan kehidupan etnis Belanda yang dominan mewah dan glamor dalam sehari-hari (Susanti A, 2013. 451). 
Pribumi khususnya Jawa cenderung masih berpegang terhadap warisan budaya.agama, tata karma dan etika. Cara berperilaku dengan orang lain terlebih dengan orang yang lebih tua. Dalam praktek kehidupan sehari-hari masyarakat Jawa memiliki tata krama dalam bertingkah laku seperti bersikap sesuai dengan derajat masing-masing yang artinya sesuai dengan strata kehidupan dan juga umur mempengaruhi aspek ini.Masyarakat Jawa menyatakan sesuatu dengan kiasan bisa disebut juga tidak langsung (Marzuki, 2006: 2).Masyarakat Jawa menghindari sikap yang menunjukkan ketidakmampuan mengontrol diri dengan sikap kasar atau melawan secara langsung.Sangat jelas disini bahwa masyarakat Jawa begitu lembut dan halus dalam memperlihatkan emosi, tata krama, etika di kehidupan sehari-hari.

Bumi Manusia telah diterjemahkan dalam 42 bahasa asing seperti Belanda, Swedia, Jepang, China, Jerman, Inggris dan banyak lagi (Hars, 2018) Pram selalu menegaskan bahwa semua novel Bumi Manusia hanyalah fiksi dan bukan sejarah. Pram menyerahkan kepada masyarakat untuk menilai dan menafsirkan bagaimana sosok Minke. Berdasarkan hasil wawancara yang dilakukan oleh Ariel Heryanto seorang guru besar Monash Universuty, Australia yang sempat beberapa kali komunikasi dengan penulis legendaris Pramoedya baik melalui surat maupun bertatap muka disampaikan secara tertulis kepada detikcom. Bagi beliau (Pram), "Pembaca boleh menafsirkan, menikmati dan menolak karyanya dengan alasan masing-masing," akan tetapi menurut Ariel, proses pembuatannua melalui penelitian sejarah yang sangat tekun (Erwin, 2018).

Berbanding terbalik dengan Belanda hanya menghormati kalangan atas yang berpendidikan dan mengganggap budayanya lebih tinggi dari budaya mana pun termasuk budaya Jawa yang masih kental dengan sembah sujudnya pada masa itu (Kompasiana, 2018) Selama masa kolonial, Belanda melakukan diskriminasi struktural pendidikan dimana pendidikan hanya dapat diakses oleh kaum bangsawan dan hanya mereka yang dapat memiliki kedekatan dengan Belanda (Fajar, 2011: 179).

Di balik kesuksesan Novel legendaris Bumi Manusia yang bertahan hingga detik ini tentu tidak semulus yang dibayangkan.Konsep novel yang ditulis oleh Pram menyebabkan banyaknya prasangka negatif.Pram diduga sebagai sastrawan berideologi komunis. Sehingga novel ini ditarik izin edarnya dan tidak boleh dibaca di Indonesia (Pigome, 2011 : 109). Berkali kali karya Pram dilarang terbit dan dibakar bahkan ditarik izin edarnya sehingga untuk membaca karya Pram harus secara diam-diam pada masa itu.Namun bagi Pram menulis adalah tugas pribadi dan tugas Nasional sehingga hal itu tidak menjadi halangan bagi Pram dalam menulis (Hars, 2018).

Preamoedya Ananta Toer dengan jelas mengungkapkan permasalahan dan ketidakadilan di era kolonialisme Belanda, strata sosial dan represi massa terhadap wanita (Agnes, 2018). Satra sosial terhadap perbedaan ras budaya Jawa dan Belanda sangat gamblang diceritakan oleh Pram melalui lika liku kehidupan Minke yang memiliki darah Pribumi Jawa akan tetapi mengagungkan budaya Eropa.

Oleh karena itu berdasarkan, latar belakang permasalahan tersebut dapat dirumuskan bebeerapa permasalahan yaitu bagaimana Perbandingan budaya Pribumi dan Belanda yang ditampilkan pada novel Bumi Manusia Melalui Pendekatan framing?

\section{KAJIAN TEORITIS}

Analisis framing, metode yang lahir dari elaborasi terus menerus terhadap pendekatan analisis wacana, dengan tujuan agar menghasilkan metode yang up-to-date untuk memahami fenomena - fenomena media mutakhir.Analisis framing merupakan suatu tradisi dalam ranah studi 
komunikasi yang menonjolkan pendekatan multidisipliner dalam menganalisis pesan - pesan tertulis maupun lisan.

Yunidar (2009:63-65) seiring perkembangan ilmu komunikasi analisis framing mempunyai asumsi bahwa wacana media massa mempunyai peran yang sangat strategis dalam menentukan apa yang penting atau signifikan dari public dari bermacam macam isu dan persoalan yang hadir dalam wacana public.framing dapat dipandang sebagai penempatan informasi - informasi dalam konteks yang khas sehingga elemen isu tertentu mendapat alokasi lebih besar dalam kognisi individu, sehingga lebih besar pula keinginannya untuk mempengaruhi pertimbangan individu. Dalam penelitian framing yang menjadi titik persoalan adalah bagaimana realitas atau peristiwa dikonstruksi oleh media massa. Sehingga yang menjadi titik perhatian bukan apakah media massa memberitakan negative atau psotif, melainkan bagaimana bingkai yang dikembangkan oleh media massa tersebut.

\begin{tabular}{|c|}
\hline \\
\hline FRAMING DEVICES \\
\hline 2. Exemplars \\
\hline 3. Catchphrases \\
\hline 4. Depections
\end{tabular}

\section{METODOLOGI}

Penelitian ini menggunakan library research, metode analisis framing model Gamson dan Modigliani.Eriyanto (2018:262) Keberadaan dari suatu package terlihat dari adanya gagasan sentral yang kemudian didukung oleh perangkat-perangkat wacana seperti; kata, kalimat, pemakaian gambar atau grafik tertentu, perposisi dan semua elemen struktur wacana mengarah keapada ide tertentu dan mendukung ide sentral dari suatu ide. Penulis akan menunjukkan elemen-elemen yang membangun cerminan pembingkaian budaya jawa dengan beberapa dioalog maupun penggalan kutipan yang ada didalam novel Bumi Manusia.

\section{HASIL DAN PEMBAHASAN}

Dari novel Bumi Manusia Pram sebagai penulis novel menyampaikan kritiknya terhadap bangsa Eropa Belanda yang menampilkan sikap rekonstruksi pada masa tradisional dimana bangsa Eropa memiliki sifat etnosentrisme.Seperti kutipan oleh Said (Suratno, 2013:1) masyarakat Barat memandang masyarakat Timur sebagai sosok the Orient.Sementara itu, masyarakat Barat memandang dirinya sebagai sosok the Occident. Dengan kata lain, masyarakat Barat ada di posisi superiuor sedangkan masyarakat timur diposisi inferior. Faruk 
(Suratno, 2013:1) menyatakan bahwa penjajah menempatkan diri sebagai subjek dengan arogansi dan superioritasnya di hadapan masyarakat pribumi.

Pram, sebagai penulis novel ini menggambarkan dua kebudayan yang sangat bertolak belakang.Dapat dilihat dari core beberapa kutipan-kutipan diatas bagaimana Minke yang sudah berinteraksi, bergaul dengan bangsa Eropa karena bersekolah di H.B.S yang merupakan sekolah elit dimana Pribumi yang bersekolah disana merupakan minoritas.Yang berhak mendapatkan pendidikan Eropa di H.B.S adalah anak-anak dari keturunan Belanda totok, Indo dan keturunuan priyai.Minke merupakan keturunan priyai.

Sebagai anak yang telah berkembang dan mendapatkan pendidikan Eropa Belanda, kritikan Pram terhadap kebiasaan pribumi dihadapan Belanda. Hal ini dapat dilihat dari beberapa kutipan dialog yang terdapat pada metaphorse dan appeals to principle alat yang digunakan untuk memperjelas bagaimana pribumi merendahkan diri untuk menghargai strata tinggi. Pada tahun 1850, pemerintah Belanda menetapkan sistem stratifikasi sosial penduduk Hindia-Belandaberdasarkan politik, ekonomi, dan sosial secara berjenjang. Yaitu; (a) Bangsa Belanda dengan Indo (b) bangsa Timur asing, misalnya Cina, Arab dan terakhir (c) masyarakat pribumi (Suratmo, 2013:2)

Pengagungan dan orientasi terhadap status sosial dan simbolisasi golongan priyai pada rakyat kecil.Oleh karena itu sering diupayaan oleh rakyat biasa sebagai bentuk penyetaraan status sosial yang merupakan syarat dan lambang status sosial merupakan syarat dan lambang status priyai uang diidealisasikan.Dalam sistem strattifikasi kolonialisme, masyarakatpribumi memiliki posisi lebih rendah, baik dibandingkan dengaorang-orang Belanda maupun bangsa Timur asing seperti Arab dan Cina. Dalam ikatan ini, sudah barang tentu terjadi idealism pada kelompok berstatus bawah (pribumi) terhadap golongan yang berstatus sosial yang lebih tinggi terlebih lagi setelah muncul penetapan status sosial baru sebgaai akibat kebijakan penguasa Belanda (Suratmo, 2013:2)

Nyai Ontosoroh seorang wanita pribumi yang menjadi gundik sebab ayahnya yang menginginkan suatu jabatan sehingga "menjual" nyai Ontosoroh kepada seorang totok Belanda pada masa itu nyai atau gundik dipandnag memiliki normal yang tidak terpuji dan bukan suatu pekerjaan yang baik. Nyai yang memiliki dendam menjadi perempuan yang mandiri dan kuat karena merasa tidak bisa mempercayai orang lain sendiri selain orang lain. Dengan kekuatan yang ia miliki ia belajar otodidak dan mampu bertahan hidup menjadi perempuan yang nyaris sama dengan wanita Belanda yang berpendidikan. Menentang dan memilih tidak berdamai dengan takdirnya yang merupakan seorang wanita pribumi yang menggundik.

Perbedaan budaya antara Pribumi dengan Belanda sering tampak dari sosok Minke dan Nyai Ontosoroh. Apalagi Nyai Ontosoroh yang memiliki perbedaan mencolok dengan wanita pribumi yang dipingit, dibatasi pergaulan dan hanya tau pekerjaan rumah tangga saja di usia remaja. Cara mendidik anakpun juga mencolok jika perempuan Pribumi tidak setegas dan sehalus Nyai Ontosoroh.

\subsection{Core Frame (Elemen Inti)}

Pada core frame dapat dijumpai bagaimana Pram memberikan perbandingan melalui pendidikan yang didapatkan oleh Jawa-Belanda dan perbandingan kecerdasan pribumi dan Belanda pengetahuan termasuk kedalam tujuh unsur kebudayaan universal. Manusia memiliki akal pikiran dan pengetahuan terkai tentang alam yang ada disekelilingnya.Pengetauan didapatkan dari lingkungan hidup yang mampu membentuk pola pikir dapat menjadi Minke 
dan Nyai Ontosoroh termasuk pembeda budaya antara Pribumi dan Eropa Belanda dalam hal pengetahuan.

Kebudayaan adalah suatu kebiasaan yang akan dilakukan terus menerus dan turun temurun yang akan diwarisi nenek moyang kepada anak cucunya kelak. Pada novel Bumi Manusia Pram menggambarkan kebudayaan atau kebiasaan merendahkan diri kepada petinggi dan yang memiliki kekuasaan seperti pada novel Bumi Manusia yang berkuaasa saat itu merupakan Belanda sebagai strata tertinggi.

Pada core frame novel Bumi Manusia dapat dilihat pola pikir tentang betapa tingginya Eropa Belanda didalam lingkungan baik strata maupun sosial sehingga membentuk pola pikir bahwasannya sangat penting memiliki darah Eropa Belanda agar dapat membantu terhadap anak cucu kelak dan membentuk tindakan oleh Robert Suurhof yang membenci wanita Pribumi dan menyukai wanita totok atau Indo pada masa itu.

\subsection{Condensing Symbols}

Melalui beberapa subjek condensing simbol yang telah dikumpulkan dapat dilihat perbedaan budaya terhadap sistem kemasyarakatan yang memiliki strata didalam novel Bumi Manusia dan strata terendah ada pada pribumi Jawa.Salah satu bentuk budaya pribumi Jawa dicerminkan melalui pembingkaian Pramoedya adalah pribumi Jawa yang telah turun temurun memiliki kebiasaan memberikan penghormatan kepada orang yang lebih berkuasa melakukan sembah sujud untuk menghargainya.

Pram beberapa kali menggunakan metamorfoasa kiasan untuk mengkritik betapa kecilnya bangsa Jawa karena mau mengalah dan terinjak-injak oleh penguasa. "Seperti keong dan menyembah seorang raja" dan "Sampai sedater tanah kalau mungkin" menggambarkan sikap menyembah dan berjalan berlutut tidak menggunakan kaki dan merangkak memberi sembah kepada orang yang lebih tinggi.Kritikan Pram terhadap keengganan merendahkan diri dan mau mengalah terinjak-injak sangat jelas melalui metafora yang digunakan Pram.

Catchphrases menekankan sudut pandang Pram mengenai pergaulan pada masa itu.Dimana memiliki kebangsaan Belanda dirasa sangat penting.Karena keberpihakan hukum, strata, kebijakan semua yang menduduki puncak teratas adalah keturunan Eropa Belanda.Perbedaan budaya yang menonjol disini adalah kesetaraan sosial yang mengikuti paramida strata sosial.

Junus (Suratno, 2013:12) menjelaskan salah satu perbedaan antara negerti terjajah dan penjajah adalah penjajah dianggap lebih maju.Penjajah memilki kemampuan untuk menyufatkan terjajah.Pribumi dipandang sebagai masyarakat terbelakang dan primitive sehingga perlu dieksploitasi menuju kehidupan modern.Keadaan tersebut menyebabkan terjajah memandan penjajah lebih tinggi.

Hal ini dapat dilihat dari kutipan-kutipan yang mengarah pada keinginan seorangan menjadi Indo, rendahnya opini seseorang terhadap anak yang tidak memiliki nama keluarga. Karena memiliki keturunan Belanda pada maa itu dapat menjadi jaminan dan tidak tersisih kedudukannya dimata masyarakat.Pada masa out Minke adalah keturunan priyai sehingga mendapatkan pendidikan yang layak dan tidak seperti pribumi lainnya yang berladang.

Didalam kondensing simbol, terdapat exemplars merupakan subjek dari kondenisng simbol untuk menguraikan fakta yang diisut oleh suatu isu.Disini isu adalah kebudayaan yang berbeda sehingga mempengaruhi pola hidup masyarakat Pribumi Jawa dan Belanda pada masa itu. Melalui tokoh pribumi Pram menggambarkan perbandingan wanita Eropa Belanda dan wanita Pribumi yang bertolak belakang akan tetapi pada Nyai Ontosoroh menjadi majemuk, 
memilki darah dan jiwa Pribumi namun memiliki sikap, etika dan mental yang dimiliki wanita Belanda yang terpelajar.

Pada masa tradisional dulunya terdapat tradisi pingitan dan pengawasan yang ketat untuk membatasi pergaulan seorang gadis dengan pria.Wanita terpelajar lebih berpeluang bergaul secara terbuka bersama teman-temannya dan pemakaian bahasa Belanda dalam pergaulan pemuda-pemudi terpelajar juga mempengaruhi pola pikir yang lebih terbuka.

Juga dapat perbedaan budaya pada peralatan dan perlengkapan hidup yang mencolok perbedaannya antara wanita pribumi dan wanita Eropa.wanita pribumi menggunakan kemben dan bekerja didapur atau bekerja membantu diladang. Sementara nyai Ontosoroh bekerja diperusahaan yang biasanya dilakukan wanita Eropa nyai Ontosoroh juga mempekerjakan wanita pribumi dengan menggunakan baju blacu dan bekerja pada pabrik yang biasanya merupakan kebiasaan pekerjaan bwanita Belanda.Disini sudah memperlihatkan perbedaan kebiasaan atau kebudayaan turun temurun terhadap kebutuhan hidup dan pekerjaan wanita.

Depictions merupakan penggambaran fakta atau isu tertentu drngan menggunakan kalimat konotatif, istilah, leksikon untuk melabeli sesuatu.Untuk menggiring kepada tujuan menguatkan harapan, posisi moral dan perubahan.Biasanya pemakaian kata diniatkan untuk membangkitkan prasangka shingga mampu menempatkan seseorang atau pihak tertentu pada poisi tidak berdaya karena kekuasaaaan konotasinya mampu melakikan kekerasan simbolik.

Depiction merupakan gambaran bagaimana pribumi direndahkan oleh Eropa.mampu merepresentasikan keadaan Pribumi pada masa itu dengan memiliki strata terendah. Keadaan yang membuat adanya penilaian tinggi dari pibumi terhadap Belanda. Penilaian dari masyarakat pribumi seperti itu menyankan munculnya orientasi pribumi terhadap budaya bangsa penjajah (Belanda) munculnya sikap ini disebabkan bebrapa faktor seperti yang jelaskan Faruk (Suratno, 2013:12) latar belakang budaya Jawa berupa orientasi masyarakat dari kelompok masyarakat strata sosial rendah (Pribumi) untuk meniru masyarakat dari strata sosial yang lebih tinggi (Belanda) dan Foulcher, tt dan Junus (Suratno, 2013:13) menambahkan sebagai akibat sistem pendidikan Eropa yang dikembangkan oleh kolonialisme Belanda yang menyebabkan kebenaran penjajah tidak dapat disanggah oleh masyarakat terjajah.

Menurut Bhaba dan Parry (Suratno, 2013:13) Keberadaan pribumi tidak pada pertentangan biner melainkan hubungan yang berjenjang dan penjajah menempatkan disinya sebagai master. Bahkan, dalam pandangan Belanda, pribumi Jawa ditempatkan atau dipahami sebagai kelompok yang memiliki perean korporeal, bersifat wadog, liat, instingtif dan kasar sehingga terbua peluang untuk penguasa sebagai bagian integral dari sistem kolonialisme

Minke yang telah bergaul dengan bangsa Eropa Belanda merasa keberatan Annalies menggunakan bahasa jawa dan lebih memilih menggunakan bahasa Indonesia.Bahasa termasuk dari bagian budaya universal baik verbal maupun nonverbal.Hal ini dipengaruhi dalam bahasa jawa memiliki tingkatan yang terikat yang unik atas etika dalam berbicara dengan yang lebih tua, orang yang memiliki strata sosial yang lebih tinggi bahkan dari perempuan ke laki-laki maupun sebaliknya di atur.

Sikap budaya dapat dilihat dari segi bentuk atau model perilaku yang terjadi pada wanita pribumi. Dari pemakaian bahasa tampak pergaulan yang lebih terbuka sejaland engan pemakaian sapaan bahasa Belanda (Suratno, 2013:81)

Selanjutnya Roots yang merupakan bagian dari reasoning device yang merupakan penekanan untuk melihat suatu isu merupakan pembenaran isu yang memiliki sebab akibat. Sebab akibat yang dimaksudkan didalam kutipan sebelumnya adalah bagaimana orang pribumi bila menginginkan sesuatu atau jabatan suka "menjilat" dan mau melakukan apapun untuk 
Belanda sehingga menuruti kehendak Belanda untuk menjual anaknya sendiri untuk dijadikan gundik orang Belanda. Hal ini menyebabkan semakin rendahnya harga diri pribumi dihadapan bangsa Belanda.

Hal ini dipengaruhi perbedaan mata pencaharian yang juga termasuk unsur kebudayaan yang universal.Mata pencaharian pribumi dahulunya dengan bercocok tanam dan bekerja kepada totok atau Indo.Oleh karena itu untuk mendapatkan kenaikan jabatan atau kepentingan pribumi rela menjilat dan bersikap sebaik mungkin bahkan merendahkan diri sendiri untuk dapat dilihat oleh Belanda totok maupun Indo yang memiliki harta dan kekuasaan yang lebih pada masa itu.

Appeal To PrincipleMerupakan pemikiran, prinsip, klaim moral sebagai argumentasi pembenaran membangun suatu berita, berupa pepatah, cerita rakyat, mitos, doktrin, ajaran dan sejenisnya. Appeal to principle yang apriori atau anggapan yang belum bisa diketahui, menjabarkan suatu ajaran tanpa ktitik sama sekali, simplistic atau bisa dikatakan bersifat terlalu disederhanakan sehingga tidak mungkin dan monokausal (nonlogis) atau merupakan proses penulisan analisis sebab dan akibat yang hanya memiliki satu sebab saja bertujuan membuat khalayak tak berdaya menyanggah argumentasi. Fokusnya, memanipulasi emosi agar mengarah ke sifat, waktu, tempat, cara tertentu, serta membuatnya tertutup atau keras dari penalaran lain (Sobur, 2016 180)

"Dia bangga menjadi orang Jawa, dan itu baik selama dia punya perasaan hargadiri sebagai pribadi maupun sebagai anak bansa.Jangan seperti bangsanya pada umumnya, mereka merasa sebgaia bangsa tiada tara di dunia ini bila berada di antara mereka sendiri. Begitu di dekat seorang Eropa, seorang saja, sudah melata, bahkan mengangkat pandangpun tak ada keberanian lagi. "'(Hal 286-287 paragraf 3)

Sebenarnya appeal to principle ini menggambarkan sebab akibat yang hampir sama dengan roots. Karena pendapat atau pemikiran oleh tuan Asisten Residen mengenai pribumi disebabkan sikap pribumi yang mau melakukan apapun untuk mendapatkan perhatian dari golongan Eropa Belanda.

Koentjaraningrat, didalam bukunya menjelaskan tiadanya pendidikan menyebabkan penduduk desa tidak memperoleh kesempatan untuk mengembangkan imajinasi terhadap ekonominya.Dengan meluasnya usaha dari perkebunan-perkebunan rakyat setelah tahun 1880 para petani mpenduduk desa itu makin jauh tertinggal. Mereka terdesak ketaraf subsistensi, tidak hanya oleh kekuatan ekonomi liberal, tetapi juga oleh golongan pegawai Belanda maaupu Pribumi yang gila hormat dan gila kekuasaan dan yang memiliki dalih untuk ketertiban umumm ingin mempertahankan status-quo atau status yang tetap masyarakat semi-feodal (yang berhubungan dengan susunan masyarakat dikuasai oleh kaum bangsawan baik cara hidup, sikap, tingkah laku) lengkap dengan orientasi nilai-budayanya yang tradisional (Koentjaraningrat, 1984:69).

Seperti uraian diatas dapat dikaitakn dengan bangsa belanda yang memilikikekuasaan atau starata tertinggi yang dimiliki bangsa Belanda menyebabkan pribumi berlomba lomba mencuri perhatian Eropa Belanda agar mendapatkan hasil atau mempertahankan status sosial, naik jabatan sesuai dengan kepentingan pribumi pada masa itu. Dengan pribumi yang merendahkan diri dan mau melakukan apapun untuk bangsa Belanda membuat Tuan Asisten Residen memiliki pemikiran buruk terhadap pribumi.

\section{PENUTUP}


Perbedaan budaya yang terdapat di dalam novel Bumi Manusia tidak hanya memperlihatkan perbedaan-perbedaan pakaian antara dua budaya yang sudah pasti berbeda.Akan tetapi perbedaan di sini juga terhadap pola pikir dan lingkungan yang mempengaruhi perbedaan pola pikir dan tingkah laku.Pramoedya Ananta Toer membingkai budaya di sini juga melalui pendidikan, agama dan lebih kepada pedalaman atau kepribadian jiwa seseorang juga dipengaruhi oleh budaya.Pribumi masih dipengaruhi sistem feodal didalam novel bumi manusia dimana penguasa mengendalikan sistem dan kekuasaan yang ada pada masyarakat.Pram mengkonstruksikan realitas suatu nilai-nilai nasionalisme.Walaupun mengagumi budaya yang dimiliki Belanda Minke juga tidak terima jiwa pribumi direndahkan melalui kesetaraan dimana pribumi menduduki tempat paling bawah.

\section{DAFTAR PUSTAKA}

Chrisanty, Priscilla. Konstruksi Realitas Keotoriteran Presiden Sukarno dalam Novel :AnalisisFraming Teks Novel The year of Living Dangerously. Jurnal Komunikasi Indonesia. Vol I(I) : $31-35$

Dariyanto, Erwin. 2018. Misteri Sosok Minke dalam Bumi Manusia.https://news.detik.com/berita/d-4040498/misteri-sosok-minke-dalam-bumimanusia diakses pada 24/03/19 Pkl 19:00 WIB.

Fajar, Yusri. Negosiasi Identitas Pribumi Dan Belanda Dalam Sastra Poskolonial Indonesia Komtemporer.Jurnal Literasi. Vol I (2) : 178-186.

Hars, Akbar. 2018. Review Novel Bumi Manusia, Karya Pramoedya Ananta Toer. https://www.kompasiana.com/akbarharsofi/5a695bd9bde5755f803f2042/review-novelbumi-manusia-karya-pramoedya-ananta-toer?page=all diakses pada 23/03/19 Pkl 09:12 WIB.

Hastuti, Nur. Novel Bumi Manusia Karya Pramoedya Ananta Toer Kajian Sosioligi Sastra. Jurnal Humanika. Vol XXV (1): 64-72.

Marzuki. 2006. Tradisi dan Budaya Masyarakat Jawa Dalam Perspektif Islam. http://staffnew.uny.ac.id/upload/132001803/lainlain/Dr.+Marzuki,+M.Ag_.+Tradisi+d an+Budaya+Masyarakat+Jawa+dalam+Perspektif+Islam.pdf diakses pada 23/03/19 Pkl. 19:33 WIB.

Pigome, r. 2011.Pertentangan Kelas di Indonesoa Dalam Novel Bumi Manusia Karya Pramoedya Ananta Toer.Jurnal Pendidikan dan Sastra. Vol X (1): 109-125.

Suranto, Pardi. 2013. Masyarakat Jawa \& Budaya Barat.Yogyakarta : Adi Wacana

Susanti, Anik. 2013. Akulturasi Budaya dan Jawa (Kajian Historis Pada Kasus Kuliner Sup dan Bistik Jawa Tahun 1900-1942).Jurnal Pendidikan Sejarah. Vol I(3) : 450-460.

Tia, Agnes. 2018. Mengingat Lagi 'Bumi Manusia' Pramoedya Ananta Toer yang Kontroversial. https://hot.detik.com/book/d-4038191/mengingat-lagi-bumi-manusia-pramoedyaananta-toer-yang-kontroversial diakses pada 21/05/19 Pk1. 22:58 WIB.

Yunidar, 2008.Analisis Framing Terhadap Pemberitaan Kompas dan Republika Semala Darurat Militer Di Aceh. Banda Aceh: Ar-Rijal Institute. 